\title{
Low-level ozone exposure induces airways inflammation and modifies cell surface phenotypes in healthy humans
}

\author{
Neil E. Alexis ${ }^{1,3}$, John C. Lay ${ }^{1,3}$, Milan Hazucha ${ }^{1,2}$, Bradford Harris ${ }^{1,3}$, Michelle L \\ Hernandez ${ }^{1,3}$, Philip A. Bromberg ${ }^{1,2}$, Howard Kehrl ${ }^{4}$, David Diaz-Sanchez ${ }^{4}$, Chong Kim ${ }^{4}$, \\ Robert B. Devlin ${ }^{4}$, and David B. Peden ${ }^{1,2,3}$ \\ ${ }^{1}$ Center for Environmental Medicine, Asthma and Lung Biology, University of North Carolina \\ School of Medicine, Chapel Hill, North Carolina, USA \\ ${ }^{2}$ Department of Medicine, University of North Carolina School of Medicine, Chapel Hill, North \\ Carolina, USA \\ ${ }^{3}$ Department of Pediatrics, University of North Carolina School of Medicine, Chapel Hill, North \\ Carolina, USA \\ ${ }^{4}$ Environmental Public Health Division, National Health and Environmental Effects Research \\ Laboratory, US Environmental Protection Agency, Research Triangle Park, North Carolina, USA
}

\section{Abstract}

The effects of low-level ozone exposure $(0.08 \mathrm{ppm})$ on pulmonary function in healthy young adults are well known; however, much less is known about the inflammatory and immunomodulatory effects of low-level ozone in the airways. Techniques such as induced sputum and flow cytometry make it possible to examine airways inflammatory responses and changes in immune cell surface phenotypes following low-level ozone exposure. The purpose of this study was to determine if exposure to 0.08 parts per million ozone for $6.6 \mathrm{~h}$ induces inflammation and modifies immune cell surface phenotypes in the airways of healthy adult subjects. Fifteen normal volunteers underwent an established 0.08 part per million ozone exposure protocol to characterize the effect of ozone on airways inflammation and immune cell surface phenotypes. Induced sputum and flow cytometry were used to assess these endpoints $24 \mathrm{~h}$ before and $18 \mathrm{~h}$ after exposure. The results showed that exposure to $0.08 \mathrm{ppm}$ ozone for $6.6 \mathrm{~h}$ induced increased airway neutrophils, monocytes, and dendritic cells and modified the expression of CD14, HLA-DR, CD80, and CD86 on monocytes $18 \mathrm{~h}$ following exposure. Exposure to 0.08 parts per million ozone is associated with increased airways inflammation and promotion of antigen-presenting cell phenotypes 18 hours following exposure. These findings need to be replicated in a similar experiment that includes a control air exposure.

\footnotetext{
(C) 2010 Informa UK Ltd

Address for Correspondence: Neil E. Alexis, PhD, Center for Environmental Medicine, Asthma, and Lung Biology, 104 Mason Farm Road, The University of North Carolina School of Medicine, Chapel Hill, NC 27599-7310, USA. Neil_Alexis@ med.unc.edu.

Disclaimer: Although the research described in this article has been funded wholly or in part by the United States Environmental Protection Agency through cooperative agreement CR-83346301 with the Center for Environmental Medicine and Lung Biology at the University of North Carolina at Chapel Hill, it has not been subjected to the Agency's required peer and policy review, and therefore does not necessarily reflect the views of the Agency and no official endorsement should be inferred.

The authors have no competing financial or nonfinancial interests to disclose.
} 


\section{Keywords}

Antigen-presenting cells; dendritic cell; inflammation; macrophage; ozone; pollution; polymorphonu-clear neutrophil

\section{Introduction}

In controlled exposure studies in which humans have been exposed for $2 \mathrm{~h}$ to $\mathrm{O}_{3}$ levels ranging from 0.125 to $0.4 \mathrm{ppm}, \mathrm{O}_{3}$ has been reported to induce an immediate effect on lung function that results in a transient neurogenic restrictive defect, as well as increased airway hyperresponsiveness and inflammation, both of which may persist for $>24 \mathrm{~h}$ (Schwela, 2000). Of these three main responses, pulmonary function has been extensively examined whereas inflammation, particularly at concentration levels at or near the 8-h-daily average National Ambient Air Quality Standard (NAAQS) of 0.08 ppm, has been the least well examined. Consequently, this paper will not address changes in pulmonary function.

The last and only study to examine the inflammatory effects of low-level $\mathrm{O}_{3}$ exposure $(0.08$ $\mathrm{ppm}$ ) for $6.6 \mathrm{~h}$ in healthy adults was performed by our group in 1991 where bronchoalveolar lavage (BAL) was used to measure cellular and biochemical changes $24 \mathrm{~h}$ following exposure (Devlin et al., 1991). We reported that exposure to $0.08 \mathrm{ppm} \mathrm{O}_{3}$ resulted in significant increases in polymormonuclear neutrophils (PMNs), prostaglandin $\mathrm{E}_{2}\left(\mathrm{PGE}_{2}\right)$, lactate dehydrogenase (LDH), interleukin (IL)- $6, \alpha_{1}$-antitrypsin, and decreased phagocytosis via the complement receptor. Since that study, $\mathrm{O}_{3}$ has been recognized as having a preferential absorption in the large central airways during exercise (Hu et al., 1994), a region not sampled by the pooled fraction of the BAL fluid reported in the 1991 study. The large airways, however, are a region of the lung from which induced sputum samples derive (Alexis et al., 2001) and hence provide a more sensitive method of characterizing the inflammatory response at low $\mathrm{O}_{3}$ concentrations. Recently, we reported in healthy subjects that sputum cell surface phenotypes are modified following a 2-h exposure to $0.4 \mathrm{ppm} \mathrm{O}_{3}$ (Alexis et al., 2004, 2008b; Lay et al., 2007). It is unknown whether these effects are occurring in the airways at $\mathrm{O}_{3}$ concentrations at or near the NAAQS level of $0.08 \mathrm{ppm}$.

The present study is an extension of our earlier report in two important ways. First, we have used induced sputum to allow selective assessment of the central airways inflammatory response, and second, employed the technique of flow cytometry to measure whether 0.08 ppm $\mathrm{O}_{3}$ can modify cell surface phenotypes that are associated with innate and acquired immune responses. These cell surface receptors include mCD14, CD80, CD86, and human leukocyte antigen (HLA)-DR. Flow cytometry will also be used to better characterize airway inflammatory cell populations such as mature and immature macrophages, newly recruited and longer resident neutrophils, monocytes, and dendritic cells (Alexis et al., 2005; 2000; Lay et al., 2007).

There is now notable interest in the public health effect of low-level $\mathrm{O}_{3}$ exposure $(\leq 0.08$ $\mathrm{ppm}$ ). As a result, we are undertaking a series of studies aimed at elucidating the impact of low-level $\mathrm{O}_{3}$ exposure on cellular and biochemical markers of airways inflammation and markers of immune modulation. This study is the first such study and serves as an initial hypothesis-generating assessment of low-level $\mathrm{O}_{3}$ exposure, since it details findings in healthy volunteers without a formal control exposure to filtered air. Follow-up studies will expand on the results reported here and include a control exposure to filtered air. 


\section{Methods}

\section{Volunteer recruitment and inclusion criteria}

This protocol was reviewed and approved by the University of North Carolina Committee on the Rights of Human Subjects (Institutional Review Board) and all subjects provided written informed consent prior to participation. All subjects underwent a physical examination, a routine blood panel with complete blood count (CBC) and differential, serum electrolytes, glucose, and liver enzymes. Female subjects had to have a negative urine pregnancy test prior to challenge and all volunteers were required to be free of chronic cardiovascular or respiratory illness, and be free of acute respiratory illness within 4 weeks of $\mathrm{O}_{3}$ challenge. All subjects had forced expiratory volume in one second $\left(\mathrm{FEV}_{1}\right)$ and forced vital capacity $(\mathrm{FVC}) \geq 80 \%$ predicted and $\mathrm{FEV}_{1} / \mathrm{FVC} \geq 80 \%$ predicted normal for height and age, and were nonsmokers with no smoking history. All subjects were screened for their ability to provide an adequate inducedsputum sample during their training session as well as establish their target minute ventilation for the exercise component of the exposure.

\section{Sputum collection}

Sputum was obtained in the morning at least $24 \mathrm{~h}$ before exposure (baseline sample) and in the morning $18 \mathrm{~h}$ following completion of the 6.6-h exposure to $0.08 \mathrm{ppm} \mathrm{O}_{3}$, using techniques previously described (Alexis et al., 2001, 2000). In brief, three 7-min inhalation periods of nebulized hypertonic saline (3\%, 4\%, 5\%) (DeVilbiss UltraNeb 99 ultrasonic nebulizer) were followed by careful expectoration of sputum into a sterile specimen cup. A cell-enriched "select" sample was obtained by manually selecting plug material from the surrounding clear saliva fluid. The total selected sample was then treated with a dilute $(0.1 \%)$ solution of dithiothrietol (DTT; Sputolysin; Calbiochem, San Diego, CA) in Dulbecco's phosphate-buffered saline (DPBS) to digest mucus. Following filtration and centrifugation $(500 \times g$, for $10 \mathrm{~min})$, aliquots of sputum supernatant were immediately frozen and stored at $-80^{\circ} \mathrm{C}$ and the cell pellet was suspended in a small volume $(0.5-1 \mathrm{ml})$ of Hanks balanced salt solution (HBSS). Cell viability (trypan blue exclusion) and total cell counts were assessed in a Neubauer hemacytometer and differential cell counts were performed on cytocentrifuged cells that were adjusted to a concentration of $1 \times 10^{6}$ cells $/ / \mathrm{ml}$ and stained with a modified Wright's stain, (Hema-Stain -3 ; Fisher Scientific). A portion of the remaining cells were immediately used for flow-cytometric assays.

\section{Sputum sample analysis}

Sputum samples were assessed for total and differential cell counts, with differential counts being achieved by both microscopic examination and flow-cytometric identification on carefully gated populations of neutrophils, macrophages, and monocytes based on positive expression of CD45 with CD16, HLA-DR, and CD14, respectively. Cell counts were expressed as cells/mg sputum. Expression of selected cell surface molecules on sputum leukocytes was quantified via multicolor flow cytometry (FCM) using a BD LSR-II flow cytometer and have been described previously (Alexis et al., 2006) (BD Immunocytometry Systems, San Jose, CA). These included molecules associated with antigen presentation and specific immunity (CD80/B7.1, CD86/B7.2, HLA-DR/MHC-II, CD11c), as well as innate immune function (CD11b/CR3, CD14/LPS receptor, CD16/Fc $\gamma$ RIII, CD64/Fc $\gamma R I)$. Sputum leukocytes were differentiated from cellular debris, bacteria, yeast, and squamous and bronchial epithelial cells by initially gating on CD45+ cells and setting appropriate filter levels (200) based on light scatter properties.

Leukocyte populations were differentiated by various specific gating strategies based on a combination of light-scattering properties and the differential expression of CD45 (pan- 
leukocyte marker) and select surface lineage markers. Dendritic cells (DCs) were identified as lineage-dim/neg/HLA-DR ${ }^{\text {high }}$ cells, the vast majority being CD11c(+).

Up- or down-regulation of specific surface molecules was quantified as a change in the mean fluorescent intensity (MFI) of the gated population. Fluorochrome-labeled antibodies were obtained from BD Biosciences (CD11b-PE-CY5, CD11c-APC, CD45-APC-Cy7, CD206-APC, HLA-DR-PerCP, Lineage Coctail-1 FITC) or Beckman-Coulter (CD14-APC, CD80-FITC, CD86-PE). Appropriate, nonspecific, labeled isotypic control antibodies were also obtained from these sources. Expression of CD11b, CD14, CD16, CD80, CD86, and HLA-DR was quantified.

Sputum supernatants were also assessed for cytokine concentration using multiplex technology (Meso ScaleDiscovery/MSD, Gaitherburg, MD). Each sample was analyzed with the Human MIP-1 alpha Ultra Sensitive Kit (lot no. K0031370) and the Human TH1/ TH2 10-Plex Ultra Sensitive Kit (lot no. K0031431). All supernatant samples were diluted 1:4 and had a final dithiothreitol (DTT) concentration of $<1 \mathrm{mM}$ where no deleterious effects have been observed using the MSD platform (Bafadhel et al., 2007).

\section{Ozone exposure and testing protocol}

The $\mathrm{O}_{3}$ exposures were conducted in an $\mathrm{O}_{3}$ exposure chamber at the US Environmental Protection Agency (EPA) Human Studies Facility on the campus of the University of North Carolina, Chapel Hill, NC (Koren et al., 1989). Volunteers underwent moderate intermittent exercise during a 6.6-h exposure to $0.08 \mathrm{ppm} \mathrm{O}_{3}$. Because repeated experimental exposure to $\mathrm{O}_{3}$ has been shown to result in adaptation of the lung function response to $\mathrm{O}_{3}$ (Folinsbee et al., 1994; Gong et al., 1997) and to modify airway inflammatory responsiveness (Arjomandi et al., 2005; Christian et al., 1998; Jorres et al., 2000) we limited our study to October through March, outside of the $\mathrm{O}_{3}$ monitoring season in North Carolina. This was done to avoid any potential masking of the effect of low-level experimental $\mathrm{O}_{3}$ exposure due to potential adaptation from repeated daily exposure to elevated ambient air $\mathrm{O}_{3}$.

Each exercise session consisted of a 50-min exercise at a level of approximately $20 \mathrm{~L} / \mathrm{min} /$ $\mathrm{m}^{2}$ body surface area (BSA) in minute ventilation followed by a 10-min rest, which was repeated six times, with exercise alternating between a treadmill and bicycle ergometer. Minute ventilation was assessed during the first two exercise sessions and settings of the treadmill or bicycle were adjusted to bring the minute ventilation to within $\pm 2 \mathrm{~L} / \mathrm{min}$ of the subject's target value. Following the third exercise session, each subject was allowed an additional 35-min break to eat lunch.

\section{Statistical analysis}

Our a priori primary hypothesis is that airway inflammation will be increased following 6.6 $\mathrm{h}$ of exposure to $0.08 \mathrm{ppm} \mathrm{O}_{3}$. Comparisons of baseline neutrophils, monocytes, macrophages, and dendritic cells expressed as cells/mg sputum to that observed the morning after $\mathrm{O}_{3}$ exposure were conducted using the Wilcoxon procedure for paired samples. To test differences between baseline and post- $\mathrm{O}_{3}$ values of expression of cell surface proteins on monocytes and macrophages, as well as differences in mediators in fluid phase supernatants of sputum samples, the Wilcoxon procedure for paired samples was used. Correlation analysis was performed using Pearsons product correlation coefficient $(R)$. Significance was set at $\alpha=.05$ for two-tailed $t$ test. 


\section{Results}

\section{Demographics and safety measures}

Fifteen healthy volunteers were recruited into this protocol. Seven (six Caucasian and one African American) were male and eight (six Caucasian and two African American) were female. The mean age was $24 \pm 1$ years (range 19-35 years). There were no adverse events associated with the exposures.

\section{Effect of $0.08 \mathrm{ppm}$ ozone on airway inflammatory cells}

Individual subject responses for neutrophils (PMNs), monocytes, macrophages, and dendritic cells (DCs) are shown in Figure 1. Mean $\pm S E M$ baseline airway neutrophilia was $349 \pm 109 \mathrm{PMNs} / \mathrm{mg}$ sputum and was significantly increased to $895 \pm 217 \mathrm{PMNs} / \mathrm{mg}$ sputum the morning following $\mathrm{O}_{3}$ challenge $(p=.001)$. Mean \pm SEM baseline airway monocytes were $68 \pm 12$ monocytes $/ \mathrm{mg}$ sputum and were increased to $128 \pm 36$ monocytes/ $\mathrm{mg}$ sputum the morning following $\mathrm{O}_{3}$ challenge $(p=.06)$. Mean \pm SEM baseline dendritic cells were $6.0 \pm 2 \mathrm{DCs} / \mathrm{mg}$ sputum and significantly increased to $11 \pm 5 \mathrm{DCs} / \mathrm{mg}$ sputum following $\mathrm{O}_{3}$ challenge $(p=.03)$, whereas mean \pm SEM baseline airway macrophage counts were $355 \pm 67$ macrophages $/ \mathrm{mg}$ sputum and decreased slightly to $337 \pm 81$ macrophages $/ \mathrm{mg}$ sputum the morning following $\mathrm{O}_{3}$ challenge.

\section{Effect of $0.08 \mathrm{ppm}$ ozone on airway cell surface phenotypes}

Expression (MFI) of CD14, CD86, and HLA-DR was significantly increased, and CD80 significantly decreased on monocytes recovered after $\mathrm{O}_{3}$ challenge (Figure 2). CD11b, CD16, and CD64 expression on airway monocytes were not significantly affected by $\mathrm{O}_{3}$ challenge. On airway macrophages, expression of $\mathrm{CD} 14$ was significantly increased and CD80 and HLA-DR significantly decreased after $\mathrm{O}_{3}$ challenge (Figure 3). Like monocytes, CD11b, CD16, and CD64 expression on airway macrophages was not significantly altered after $\mathrm{O}_{3}$ challenge. We observed no significant changes in any of the cell surface phenotypes on neutrophils or dendritic cells following $\mathrm{O}_{3}$ exposure (data not shown).

\section{Airway cytokines}

We also examined sputum supernatants for a number of proinflammatory cytokines (interferon- $\gamma$, IL-1 $\beta$, IL-2, IL-4, IL-5, IL-6, IL-8, IL-10, IL-12p70, IL-13, macrophage inflammatory protein $1 \alpha[\mathrm{MIP} 1 \alpha]$, and tumor necrosis factor $\alpha[\mathrm{TNF} \alpha])$. Of these, we observed significant increases in IL-6, IL-8, IL-12p70, and TNF $\alpha$ the morning after challenge compared to baseline challenge. These results are depicted in Figure 4. Of these cytokines, correlation analysis revealed that IL-12p70 was significantly associated with the increase in dendritic cells following $\mathrm{O}_{3}$ exposure $(R=.58, p=.03)$.

\section{Discussion and conclusions}

To our knowledge, this is the only report using flow cytometry to quantify changes in airway cell populations and immunophenotype characteristics following exposure of humans to $0.08 \mathrm{ppm} \mathrm{O}_{3}$. We confirmed our earlier study by showing that this near-ambient level of ozone caused pulmonary inflammation, as evidenced by a significant increase in airway neutrophils and a number of proinflammatory cytokines. In addition, we show here that $\mathrm{O}_{3}$ exposure also caused an influx of monocytes and dendritic cells, and that airway monocytes expressed higher levels of CD14, CD80, CD86, and HLA-DR compared to those collected at baseline. These results suggest that in addition to recruiting of granulocytes to the airway, $\mathrm{O}_{3}$ exposure also results in an influx of immunomodulatory cells with modified cell surface phenotypes. It is noteworthy that we are finding ozone-induced inflammation near the current National Ambient Air Quality Standard of 0.08 ppm O 3 averaged over $8 \mathrm{~h}$. 
When we compare the results of the present study regarding neutrophil influx following 0.08 ppm O $\mathrm{O}_{3}$ exposure to those from our earlier study in 1991 (Devlin et al., 1991), we find a much greater degree of neutrophilic inflammation. This may be due in part to sputum sampling central, rather than distal, airway samples (Alexis et al., 2001). Arjomandi et al. (2005) also reported increased baseline neutrophilia in induced sputum of subjects exposed to $\mathrm{O}_{3}$ with poor correlation to more distal alveolar samples. Although inflammation in the distal airways has been observed following $\mathrm{O}_{3}$ exposure by our group and others (Devlin et al., 1991; Joad et al., 2006), data here suggest that sampling the proximal airways may be a more sensitive approach for assaying pollutant-induced inflammation, at least in the case of $\mathrm{O}_{3}$. In addition, identification and quantification of inflammatory cell populations by flow cytometry enhances the accuracy of leukocyte evaluation by reducing biases in cytospin counting, as reported by Hodge et al. (2004). In that study, Hodge and colleagues (2004) compared flow-cytometric versus manual counting of BAL cells in chronic obstructive pulmonary disease (COPD) patients and reported a tendency by cytospins to overestimate the percentage of macrophages by $5.9 \%$.

One important limitation in this study, as compared to previous ozone studies, was the absence of data in which subjects were exposed to both clean air (sham exposure) and $\mathrm{O}_{3}$ on separate occasions, in order to control for the potential effect of exercise on airways inflammation. We contend that for this initial hypothesis generation study, a strict requirement to include a sham exposure was not necessary. In our previous $\mathrm{O}_{3}$ studies where we employed sham exposures and compared cellularity of sputum (and bronchial wash) at baseline (prechallenge) versus clean air (with exercise), we found no difference between the clean air and preexposure baseline samples (Lay et al., 2007; Peden et al., 1997). We further note that in the bronchial wash study noted above, the exposure duration and exercise protocol were almost identical to the one used here, and employed the same postexposure sampling time as this study. In addition, whatever potential effect exercise may have had on our inflammatory endpoints, it would have been minimal and likely resolved $18 \mathrm{~h}$ postexposure. However, despite these data, we note that the absence of an air exposure in this study places limitations on the interpretation of the results reported here. Another limitation to note in our study was potential technician bias in processing the pre- and postexposure sputum samples because they were not formally blinded to this component. We note, however, that certain measures were in place to help reduce or avoid this potential bias, such as exposure day information was not present on the sample containers and preand postexposure samples were generally collected at the same time of day.

Although the ability of $\mathrm{O}_{3}$ to induce airway neutrophilia is well known, the effect of $\mathrm{O}_{3}$ on other inflammatory or immunomodulatory cells in the airway has been less well studied. We previously reported that $0.4 \mathrm{ppm} \mathrm{O}_{3}$ causes increases in airway monocytes, with increased expression of CD11b, CD14, CD86, and HLA-DR (Lay et al., 2007). This study extends these findings by demonstrating that even very low concentrations of $\mathrm{O}_{3}$ can alter monocyte phenotype. We have made similar observations in healthy and allergic volunteers in airway sputum recovered after inhalation challenge with 20,000 endotoxin units (Alexis et al., 2005, 2008a). These surface markers are essential to modulating key elements of both innate and acquired immunity, and may play a role in antigen presentation. Although we did not observe changes in expression of cell surface proteins on dendritic cells after $\mathrm{O}_{3}$, we did see $\mathrm{O}_{3}$-induced changes in IL-12p70 levels that correlated with increases in dendritic cells found in airway sputum after $\mathrm{O}_{3}$ exposure. IL-12p70 is secreted by activated dendritic cells and plays a significant role in antigen presentation and immune response (Trinchieri et al., 2007). Furthermore, we report increased levels of proinflammatory cytokines IL-8, IL-6, and $\mathrm{TNF} \alpha$, cytokines that are associated with an inflammatory cellular milieu, particularly neutrophils in the case of IL- 8 and monocytes and macrophages in the case of IL-6 and $\mathrm{TNF} \alpha$. The absence of any significant change in the other cytokines measured in this study 
may reflect their lack of a specific association with neutrophilic or monocyte-induced inflammation, both of which were present at $18 \mathrm{~h}$ postexposure. On the other hand, it may reflect a shorter time course of activation for these cytokines such that their levels returned to baseline values by $18 \mathrm{~h}$ postexposure.

Taken together, these observations support the idea that inhaled environmental toxicants may promote adverse health events by enhancing the numbers of immunoregulatory cells such as monocytes and dendritic cells present in the airway. Furthermore, in the case of monocytes, there appears to be a phenotype bias toward antigen presentation. We hypothesize that recruitment of such cells to the airway would enhance innate or acquired immune responses to biological material associated with particulate matter, bioaerosols, or domestic environments that contain allergens.

Consistent with our hypothesis that $\mathrm{O}_{3}$-induced influx of immunomodulatory cells to the airway modulates the adverse health effects associated with this pollutant are observations by our group and others that experimental $\mathrm{O}_{3}$ exposure enhances immediate and late-phase airway response to allergens (Bernstein et al., 2004; Peden et al., 2005). Koike and colleagues (2004) have shown that antigen-presenting cell activity of cells recovered from the respiratory tract of rodents is enhanced after $\mathrm{O}_{3}$ challenge. $\mathrm{O}_{3}$ has also been shown to enhance sensitization of infant rhesus monkeys to mite allergen, a process that clearly involves antigen presentation (Joad et al., 2006).

In this report we describe the influx of neutrophils, monocytes, and dendritic cells and their modulated surface phenotypes to the airways of healthy human volunteers the morning after exposure to $0.08 \mathrm{ppm} \mathrm{O}_{3}$, a level frequently encountered in most metropolitan areas in the United States. We hypothesize that these immunoinflammatory changes induce direct injury to the airway, and markedly increase responsiveness to other pollutants, bioaerosols, and allergens in normal healthy persons and likely in those with asthma. Enhanced antigen presentation capability will induce exaggerated T-cell responses where in the case of atopic asthma will promote Th-2 inflammation in the airway. In considering the public health implications of exposure to ambient air levels of $\mathrm{O}_{3}$, it will be important to fully understand the effect of this pollutant on inflammatory and immunomodulatory cells in the airway. Finally, the results reported in this study need to be confirmed in a subsequent study employing a control exposure.

\section{Acknowledgments}

The authors gratefully acknowledge the skillful assistance of Martha Almond, Aline Kala, Margaret Herbst, Carole Robinette, Heather Wells, Fernando Dimeo, Danuta Sujkowski, Lynne Newlin-Clapp, and Nolan Sweeny from the University of North Carolina Center for Environmental Medicine, Asthma and Lung Biology, and Maryann Bassett, Tracy Montilla, and Martin Case of the Environmental Public Health Division of the US Environmental Protection Agency in the completion of this project.

\section{Declaration of interest}

This work was supported by NIEHS grant R01ES012706 and US EPA Cooperative Agreement CR 83346301.

\section{References}

Alexis N, Soukup J, Ghio A, Becker S. Sputum phagocytes from healthy individuals are functional and activated: a flow cytometric comparison with cells in bronchoalveolar lavage and peripheral blood. Clin Immunol. 2000; 97:21-32. [PubMed: 10998314]

Alexis NE, Hu SC, Zeman K, Alter T, Bennett WD. Induced sputum derives from the central airways: Confirmation using a radiolabeled aerosol bolus delivery technique. Am J Respir Crit Care Med. 2001; 164(10 Pt 1):1964-1970. [PubMed: 11734453] 
Alexis NE, Becker S, Bromberg PA, Devlin R, Peden DB. Circulating CD11b expression correlates with the neutrophil response and airway $\mathrm{mCD} 14$ expression is enhanced following ozone exposure in humans. Clin Immunol. 2004; 111:126-131. [PubMed: 15093561]

Alexis NE, Lay JC, Almond M, Bromberg PA, Patel DD, Peden DB. Acute LPS inhalation in healthy volunteers induces dendritic cell maturation in vivo. J Allergy Clin Immunol. 2005; 115:345-350. [PubMed: 15696093]

Alexis NE, Lay JC, Zeman K, Bennett WE, Peden DB, Soukup JM, et al. Biological material on inhaled coarse fraction particulate matter activates airway phagocytes in vivo in healthy volunteers. J Allergy Clin Immunol. 2006; 117:1396-1403. [PubMed: 16751003]

Alexis NE, Brickey WJ, Lay JC, Wang Y, Roubey RA, Ting JP, et al. Development of an inhaled endotoxin challenge protocol for characterizing evoked cell surface phenotype and genomic responses of airway cells in allergic individuals. Ann Allergy Asthma Immunol. 2008a; 100:206115. [PubMed: 18426139]

Alexis NE, Lay JC, Haczku A, Gong H, Linn W, Hazucha MJ, Tal-Singer R, Peden DB. Fluticasone propionate protects against ozone-induced airways inflammation and modified immune cell activation markers in healthy volunteers. Environ Health Perspect. 2008b; 116:799-805. [PubMed: 18560537]

Arjomandi M, Witten A, Abbritti E, Reintjes K, Schmidlin I, Zhai W, et al. Repeated exposure to ozone increases alveolar macrophage recruitment into asthmatic airways. Am J Respir Crit Care Med. 2005; 172:427-432. [PubMed: 15937293]

Bafadhel M, Saha S, Siva R, McCormick M, Monteiro W, Rugman P, Dodson P, Pavord ID, Newbold $\mathrm{P}$, Brightling CE. Sputum IL-5 concentration is associated with a sputum eosinophilia and attenuated by corticosteroid therapy in COPD. Respiration. 2009; 78:256-262. [PubMed: 19478474]

Bernstein JA, Alexis N, Barnes C, Bernstein IL, Bernstein JA, Nel A, et al. Health effects of air pollution. J Allergy Clin Immunol. 2004; 114:1116-1123. [PubMed: 15536419]

Christian DL, Chen LL, Scannell CH, Ferrando RE, Welch BS, Balmes JR. Ozone-induced inflammation is attenuated with multiday exposure. Am J Respir Crit Care Med. 158:532-537. [PubMed: 9700132]

Devlin RB, McDonnell WF, Mann R, Becker S, House DE, Schreinemachers D, Koren HS. Exposure of humans to ambient levels of ozone for 6.6 hours causes cellular and biochemical changes in the lung. Am J Respir Cell Mol Biol. 1991; 4:72-81. [PubMed: 1846079]

Folinsbee LJ, Horstman DH, Kehrl HR, Harder S, Abdul-Salaam S, Ives PJ. Respiratory responses to repeated prolonged exposure to 0.12 ppm ozone. Am J Respir Crit Care Med. 1994; 149:98-105. [PubMed: 8111607]

Gong H Jr, McManus MS, Linn WS. Attenuated response to repeated daily ozone exposures in asthmatic subjects. Arch Environ Health. 1997; 52:34-41. [PubMed: 9039855]

Hodge SJ, Hodge GL, Holmes M, Reynolds PN. Flow cytometric characterization of cell populations in bronchoalveolar lavage and bronchial brushings from patients with chronic obstructive pulmonary disease. Cytom B (Clin Cytom). 2004; 61B:27-34.

Hu SC, Ben-Jebria A, Ultman JS. Longitudinal distribution of ozone absorption in the lung: effects of respiratory flow. J Appl Physiol. 1994; 77:574-583. [PubMed: 8002502]

Joad JP, Kott KS, Bric JM, Peake JL, Plopper CG, Schelegle ES, et al. Structural and functional localization of airway effects from episodic exposure of infant monkeys to allergen and/or ozone. Toxicol Appl Pharmacol. 2006; 214:237-243. [PubMed: 16466656]

Jorres RA, Holz O, Zachgo W, Timm P, Koschyk S, Muller B, et al. The effect of repeated ozone exposures on inflammatory markers in bronchoalveolar lavage fluid and mucosal biopsies. Am J Respir Crit Care Med. 161:1855-1861. [PubMed: 10852757]

Koike E, Watanabe H, Kobayashi T. Exposure to ozone enhances antigen-presenting activity concentration dependently in rats. Toxicology. 2004; 197:37-46. [PubMed: 15003332]

Koren HS, Devlin, Graham DE, Mann R, McGee MP, Horstman DH, Kozumbo WJ, Becker S, House DE, McDonnell WF. Ozone-induced inflammation in the lower airways of human subjects. Am Rev Respir Dis. 1989; 139:407-415. [PubMed: 2913889] 
Lay JC, Alexis NE, Kleeberger SR, Roubey RAS, Harris BD, Bromberg PA, Hazucha MJ, Devlin RB, Peden DB. Ozone exposure enhances expression of surface markers of innate immunity and antigen presentation on airway monocytes in healthy individuals. J Allergy Clin Immunol. 120:719-722. [PubMed: 17586033]

Peden DB. The epidemiology and genetics of asthma risk associated with air pollution. J Allergy Clin Immunol. 2005; 115:213-219. [PubMed: 15696070]

Peden DB, Boehlecke B, Horstman D, Devlin R. Prolonged acute exposure to $0.16 \mathrm{ppm}$ ozone induces eosinophilic airway inflammation in asthmatic subjects with allergies. J Allergy Clin Immunol. 1997; 100(6 Pt 1):802-808. [PubMed: 9438490]

Schwela D. Air pollution and health in urban areas. Rev Environ Health. 2000; 15:13-42. [PubMed: 10939084]

Trinchieri G, Sher A. Cooperation of Toll-like receptor signals in innate immune defence. Nat Rev Immunol. 2007; 7:179-190. [PubMed: 17318230] 

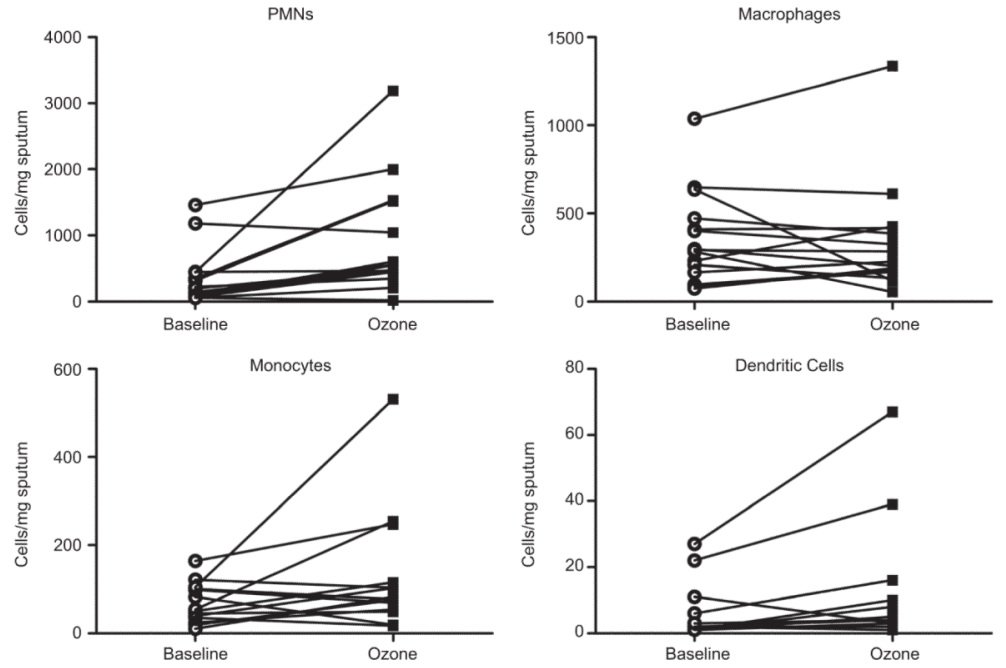

Figure 1.

Individual subject inflammatory cell responses (cells/mg sputum) following ozone exposure (closed square) compared to baseline (open circle). Neutrophils ( $p=.001$, upper left panel), macrophages $(p>.05$, upper right panel), monocytes ( $p=.06$, lower left panel), and dendritic cells $(p=.03$, lower right panel). 

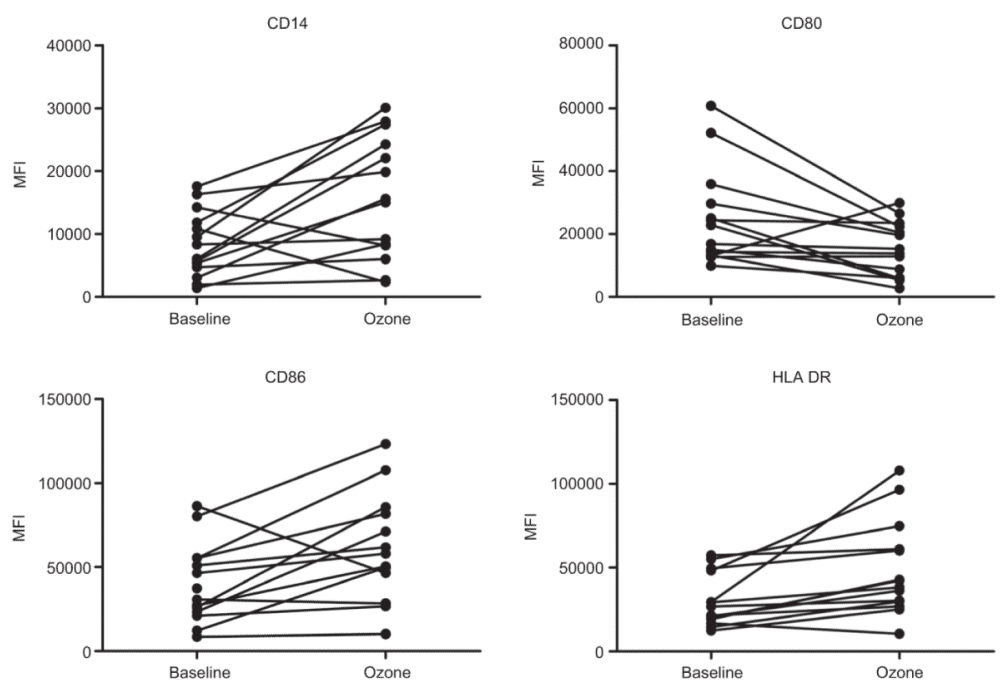

Figure 2.

Expression (MFI) of sputum monocyte surface proteins on individual subjects following ozone exposure compared to baseline. CD14 ( $p=.01$, upper left panel), CD80 ( $p=.01$, upper right panel), CD86 ( $p=.01$, lower left panel), and HLA-DR ( $p=.001$, lower right panel). 

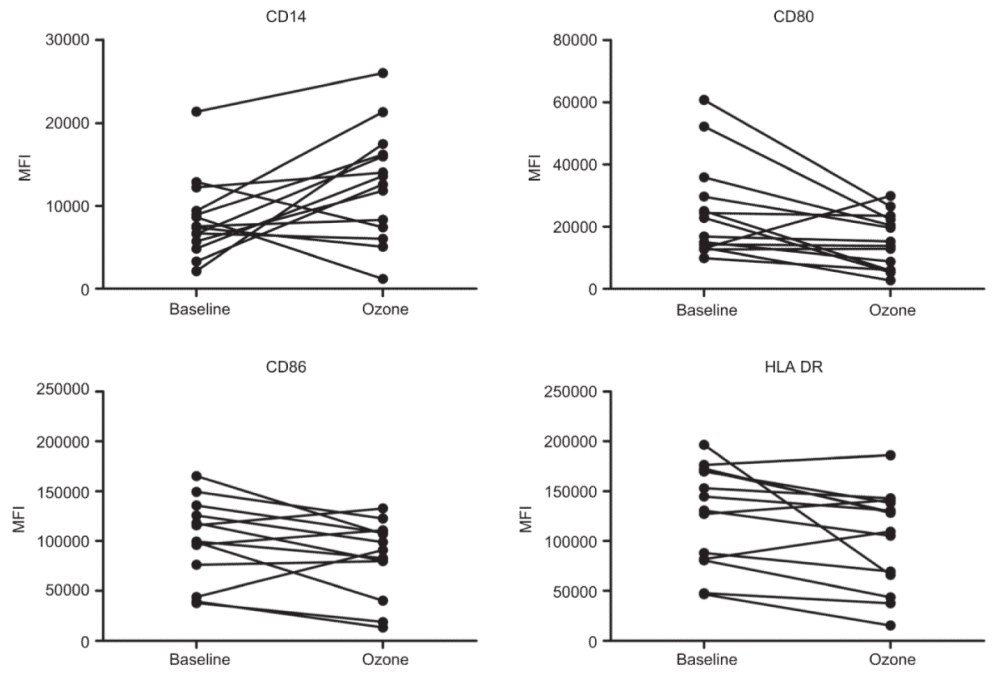

Figure 3.

Expression (MFI) of sputum macrophage surface proteins on individual subjects following ozone exposure compared to baseline. CD14 ( $p=.04$, upper left panel), CD80 ( $p=.01$, upper right panel), CD86 ( $p=.06$, lower left panel), and HLA-DR $(p=.02$, lower right panel). 

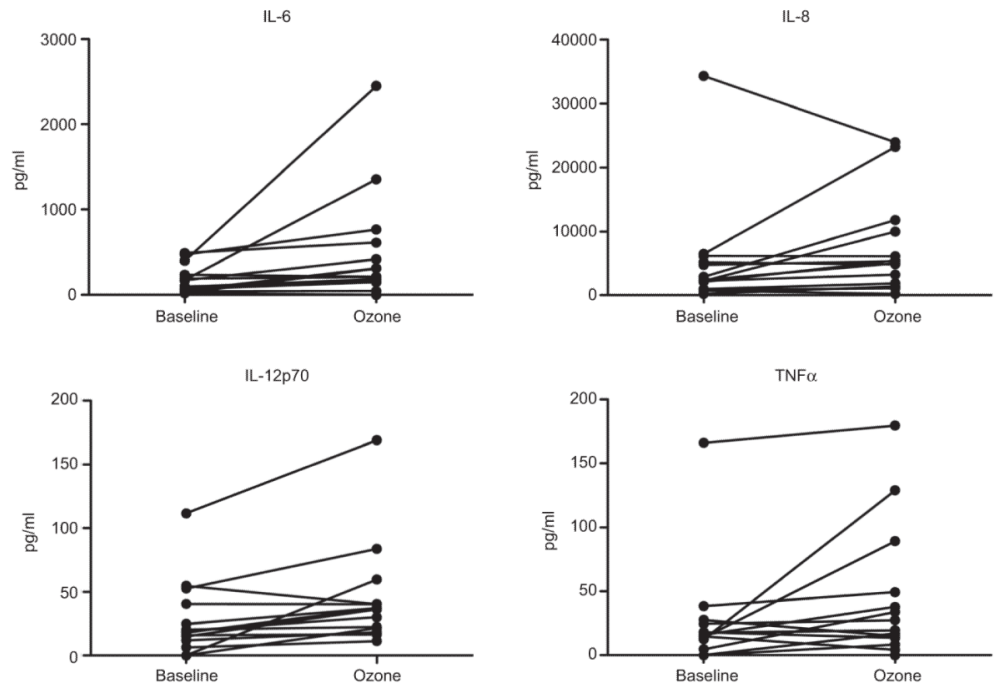

Figure 4.

Cytokine values $(\mathrm{pg} / \mathrm{ml})$ on individual subjects following ozone exposure compared to baseline. IL-6 ( $p=.02$, upper left panel), IL-8 ( $p=.05$, upper right panel), IL-12p70 ( $p=$. 004 , lower left panel), and TNF $\alpha(p=.03$, lower right panel). 